IZA DP No. 6149

Long-Term Effects of

Early Childhood Care and Education

Christopher Ruhm

Jane Waldfogel

November 2011

Forschungsinstitut

zur Zukunft der Arbeit

Institute for the Study

of Labor 


\title{
Long-Term Effects of Early Childhood Care and Education
}

\author{
Christopher Ruhm \\ University of Virginia, \\ NBER and IZA
Jane Waldfogel
Columbia University and IZA

\section{Discussion Paper No. 6149 \\ November 2011}

\author{
IZA \\ P.O. Box 7240 \\ 53072 Bonn \\ Germany \\ Phone: +49-228-3894-0 \\ Fax: +49-228-3894-180 \\ E-mail: iza@iza.org
}

\begin{abstract}
Any opinions expressed here are those of the author(s) and not those of IZA. Research published in this series may include views on policy, but the institute itself takes no institutional policy positions.

The Institute for the Study of Labor (IZA) in Bonn is a local and virtual international research center and a place of communication between science, politics and business. IZA is an independent nonprofit organization supported by Deutsche Post Foundation. The center is associated with the University of Bonn and offers a stimulating research environment through its international network, workshops and conferences, data service, project support, research visits and doctoral program. IZA engages in (i) original and internationally competitive research in all fields of labor economics, (ii) development of policy concepts, and (iii) dissemination of research results and concepts to the interested public.
\end{abstract}

IZA Discussion Papers often represent preliminary work and are circulated to encourage discussion. Citation of such a paper should account for its provisional character. A revised version may be available directly from the author. 
IZA Discussion Paper No. 6149

November 2011

\section{ABSTRACT}

\section{Long-Term Effects of Early Childhood Care and Education*}

This paper critically reviews what we know about the long-term effects of parental leave and early childhood education programs. We find only limited evidence that expansions of parental leave durations improved long-run educational or labor market outcomes of the children whose parents were affected by them, perhaps because benefits are hard to measure or confined to sub-groups, or because leave entitlements were sufficiently long, even before recent extensions, to yield most potential benefits. By contrast, expansions of early education generally yield benefits at school entry, adolescence, and for adults, particularly for disadvantaged children; however the gains may be less pronounced when high quality subsidized child care was available prior to the program expansion or when subsidies increased the use of low quality care.

JEL Classification: $\quad \mathrm{J} 13, \mathrm{~J} 18, \mathrm{~J} 48$

Keywords: parental leave, early childhood care and education

Corresponding author:

Christopher Ruhm

Frank Batten School of Leadership and Public Policy

University of Virginia

P.O. Box 400893

Charlottesville, VA 22904-4893

USA

E-mail: ruhm@virginia.edu

\footnotetext{
* Forthcoming in Nordic Economic Policy Review. We gratefully acknowledge support from the Eunice Kennedy Shriver National Institute of Child Health \& Human Development (NICHD) through R01HD047215 as well as R24HD058486. The content is solely the responsibility of the authors and does not necessarily represent the official views of NICHD or the National Institutes of Health.
} 
Early childhood has been a focus of much research and policy in recent years. Particular attention has been directed to two types of policies - parental leave, and early childhood education. Although distinct, both policy instruments alter the balance between parental care and non-parental care and education in early childhood, and may also influence the quality of the care and education that young children receive. As such, these policies are thought to not only improve child and family well-being in the all-important early childhood period but also to have the potential to improve long-term outcomes for children. The two policies can also substitute, to some extent, for each other. For example, some countries may choose to combine lengthy parental leaves with relatively limited use of early non-parental care, while others may provide shorter leaves but earlier entry into non-parental care.

Until recently, evidence on the long-term effects of these policies has been lacking, and the evidence from the new wave of studies is not always clear or consistent. Hence, in this paper, we provide a critical review of what we know, and don't know, about the long-term effects of parental leave and early childhood education, with particular focus on policies that are universal, or nearly so, for children of specified ages.

There are a variety of ways through which parental leave and universal early childhood education may affect short-and long-term developmental outcomes. This review will mostly not attempt to determine the contributions of these alternative mechanisms, or the interactions between them, in part because of limitations in existing research. However, two causal pathways deserve mention. First, as James Heckman and co-authors have emphasized (e.g. Cunha and Heckman, 2007; Heckman, 2008), the returns may be higher to investments made early in life than to those made at later ages. The key reasons are that early childhood may be a sensitive period, where the benefits are particularly high, and because early investments raise the productivity of future investments (dynamic complementarity). Kindergarten, prekindergarten and other educational related programs thus couldbe important because of the direct investments in human capital that they provide. These effects may also differ across types of children and depending on the nature of the investments. For instance, the language components of such programs may be particularly important for immigrant children whose native language differs from that of the country in which they reside. Second, there may be indirect effects. Among the most important of these may be that expanded parental leave entitlements and universal or near universal early education may increase the employment of parents - particularly mothers - by reducing the opportunity costs of work. Such employment may have positive effects if it raises family incomes or negative impacts if parental time investments in children are more productive than those obtained in non-parental settings.

The structure of the paper is as follows. We first discuss challenges in estimating the effects of the policies of interest. Next, we provide a brief overview of parental leave policies and review the evidence on the effects of these policies on child outcomes. Section three provides an overview of recent expansions in large-scale or universal early childhood education and reviews the evidence on the effects of these programs on child outcomes. In the concluding section, we discuss policy implications as well as implications for future research. 


\section{Challenges in Measuring Policy Impacts}

At the onset, we should recognize several challenges in obtaining credible and accurate estimates of the long-term effects of these early childhood policies. One issue relates to the difficulty of obtaining data that are appropriate and sufficiently detailed for this task. We would like to look at the impacts of policies years or (ideally) decades in the future, but most longitudinal data sets (e.g. the National Longitudinal Survey of Youth and Panel Study of Income Dynamics in the United States or the British Household Panel Survey or various birth cohort studies in the United Kingdom) are simply not up to this task. They generally do not follow subjects for a sufficient length of time orinclude subjects who experienced different policy regimes. When they do, the analysis samples are typically too small to provide sufficient statistical power, particularly for interventions whose effects may be reinforced or offset by moderating or mediating factors occurring in later years. It is at least partially for this reason that estimates of short-term effects are far more voluminous and, frequently, more credible than estimates of long-term effects. However, a promising development is the increased use of registry (administrative) data by researchers, mainly in Europe. Registry data have several advantages. First, in many cases information is available for long periods of time (sometimes over the full lifecycle) for large representative samples or even for the entire cohort in a country. Second, administrative data can sometimes be combined from a variety of different sources including, for example, the social insurance, education, employment, and health systems, to provide information over a variety of relevant dimensions of the individual's life. On the other hand, while rich in many ways, registry data are often quite limited in others, simply because many types of personal information are not contained in the registries. For example, there is generally no information on attitudes, many types of parental inputs (like time spent investing in children) or, in some cases, basic demographic variables such as family characteristics.

Even ignoring potential data problems, it is often difficult to identify causal effects of parental leave or early childhood education policies because of potential omitted variables biases and endogenous enactment of the policies. To provide one example, a country may put new early childhood education policies in place because they think their children are doing poorly, relative to those in other nations. Simple correlations are then likely to understate the effectiveness of the policy. Conversely, benefits of the policies may be overstated if they tend to be enacted by countries that already had relatively rich environments for child health and development.

Tremendous progress has been made in recent years developing techniques to deal with these potential problems. Three are particularly important. The first are "difference-in-difference" (or DD) estimates. In DD models, researchers identify a "treatment" group expected to be affected by the policy and a "control” group whom the policy should not influence. For instance, when considering parental leave policies it will sometimes be appropriate to use children whose mothers worked during pregnancy as the treatment group and those whose 
mothers did not as the control group. ${ }^{1}$ Differences in the outcomes of interest for children born (or reaching a relevant age) before and after implementation of a new policy will be measured, and these will be compared for the treatment and control groups. The basic assumption is that any differences observed for the control group result from factors other than the policy and that these unaccounted for factors will have the same influence on the treatment group. Removing them then allows for the estimation of causal effects of the policies. However, while helpful, DD methods are not a panacea because it is often difficult to cleanly separate individuals into treatment and control groups and because the assumption that unobserved factors influence the treatment and control groups identically may not hold. Specifically, the standard DD model includes a control for a policy main effect (a dummy variable taking the value one for periods in which the policy operates and zero otherwise) and an interaction between the policy dummy variable and an indicator for belonging to the treatment group anticipated to be affected by the policy. The key assumption is that trends in (but not levels of) the outcome variable would be the same for the treatment and control groups in the absence of the policy being implemented. If trends are not the same, or if the treatment and control groups are not cleanly defined, the interaction coefficient may understate or overestimate the true policy treatment effect.

A second approach is to use the method of instrumental variables (IV). Assume that we are interested in knowing how a variable $X$ affects an outcome $Y$ but standard regression of $Y$ on $X$ will yield biased estimates because there are unobserved influences on $Y$ that are correlated with $X$. This bias can be eliminated if an "instrument" $Z$ can be found that is correlated with $X$ but does not independently affect $Y$, other than through its correlation with $X$ (i.e. the instrument is uncorrelated with the error term in the estimation equation). For instance, we might want to estimate the effect of child care — of a particular type or quality — on child outcomes, but estimates may be biased because families do not randomly choose whether or not to use the specified type of child care. In this case, we might use child care policies (such as the availability of subsidies or the location of centers) as an instrument. IV estimates frequently encounter two problems. First, the assumption that the instrument has no independent effect on the outcome of interest may not hold. In the example just provided, it is possible that the subsidies or child care availability influence child outcomes in ways other than through changes in child care provision (e.g. through altering maternal employment or family income). Second, the effects of the instruments may be limited to a relatively small subset of the group in which we are interested and the impact of the policy on these subgroups may differ from those for the entire population of interest. ${ }^{2}$ For instance, many child care subsidies primarily or exclusively target mothers of low-income children and the effects might be quite different than those that would occur if children from higher-income families were also included.

Third, and increasingly common in recent years, is the use of regression discontinuity (RD) techniques. The key aspect of these methods involves identifying treatment and control

\footnotetext{
${ }^{1}$ However, if the decision to work during pregnancy is influenced by parental leave policies, this division into treatment and control groups may be inappropriate.

${ }^{2}$ Thus, instrumental variables models obtain what is referred to as a "local average treatment effect".
} 
groups who are otherwise very similar but because of a feature of the way the specific policy was implemented are alternatively affected and not affected by it. Consider an early childhood education policy that affects children born on or after January 1 of a given year. Researchers using RD methods might then compare children born just before and just after this date. For instance, those born in January are the treatment group while those born in December of the previous year are the control group. The critical assumption is that children born in December would have the same outcomes as those born in January were it not for implementation of the policy. Although this assumption might not hold, a variety of methods can be used to test whether it appears to be reasonable. ${ }^{3} \mathrm{RD}$ methods provide a powerful method of providing causal estimates when the design conditions are met. However, as with instrumental variables, it will often be difficult to obtain treatment effects across the full range of policy variation that is of interest.

\section{Parental leave}

\subsection{Origins and current situation}

Parental leave policies have long been a feature of European welfare states. Beginning with Bismarck at the end of the $19^{\text {th }}$ century, governments have enacted legislation to provide mothers with a period of paid and job-protected leave around the time of childbirth. ${ }^{4}$ Such leaves are thought to be essential to protect the health of mothers and also to provide them with sufficient time to provide care to vulnerable newborns. Policies have been expanded in recent decades to supply longer periods of parental leave (much of which is available to both mothers and fathers) and frequently more flexibility in its use. Since mothers typically take the vast majority of parental leave, some countries have established small amounts of dedicated paternity leave or enacted bonus arrangements where the total duration of leave available is longer if both parents use some of it. All European nations offer at least 14 weeks of paid maternity leave, with a wage replacement rate of 70 to 100 percent, with at least six months of paid leave being the norm and job-protected partially paid leave of nine months or more being common (e.g. offered in Austria, Denmark, Finland, France, Germany, Greece, Iceland, Italy, Norway, Portugal, Sweden, and the United Kingdom). Only the U.S. among advanced industrialized countries does not provide paid maternity leave as a matter of right to all working mothers (nor does it guarantee paid paternity leave).

A large body of research has examined the effects of maternity leave reforms on women's labor supply and fertility decisions, and a smaller number ofanalyses have studied consequences for infant health (e.g. see Ruhm, 1998, 2000; Tanaka, 2005). However, until

\footnotetext{
${ }^{3}$ For instance, pre-treatment and post-treatment trends can be compared and "falsification tests" can be implemented whereby expected null effects are tested for when choosing to conduct an RD analysis using a cutoff date other that of the actual policy implementation. RD and DD methods can also be combined by including, as an additional control, the difference-in-difference for groups just before and after the policy change compared to those during the same calendar time period in previous or subsequent years.

${ }^{4}$ See Ruhm (2011) for a more extensive discussion of the issues covered in this paragraph.
} 
recently, studies have not examined longer-term effects of maternity leave policies on child health and development.

The expected effects of leave policies on long-term child health and development are not completely clear a priori. First, results of the reforms will depend on whether and how they affect maternal time at home, as well as their influence on mediating factors like family income. The reach of any laws will further depend on the share and characteristics of the population covered, as well as by the specific provisions of the legislation. Generously paid maternity leave extensions would presumably induce covered women to stay home for a longer period of time, without substantially decreasing family income, while at the other extreme, unpaid leave would have less effect on women's behavior and would, for those taking it up, reduce family income unless there are offsetting increases in spousal labor supply. Second, the effect of the reforms will depend on when in childhood they occur. The consequences could be very different for having a mother at home in the first weeks and months of the child's life than later in infancy or toddlerhood.For instance, several studies have shown that maternity leave extensions early in life increase the likelihood and duration of breast-feeding (e.g. Baker and Milligan, 2008), which may in turn be beneficial for child health and development, but such effects are probably less important when considering reforms that extend leave later in the first year of life or in subsequent years. Third, the effects of any extensions will depend on the counter-factual. Where the quality of child care is high, children may benefit less from parental leave extensions than they do in situations where the quality of non-parental care is low or high quality care is difficult to afford. This discussion suggests that the effects of maternity leave reforms may not be consistent across countries or situations and indeed that is the case, as we shall see below.

\subsection{The evidence}

There are now four analyses of the effects of maternity leave on young adult or adolescent outcomes, all of which take advantage of policy changes in Europe that extended the period of leave and thus provide information about the effects of allowing mothers to stay home for a longer period of time in the first year or years of a child's life. ${ }^{5}$ We begin our review with these studies and then turn to evidence from research oneffects on younger children. For the most part, these latter studies examine the consequences of the recent Canadian maternity leave extensions, and differences in U.S. state maternity leave policies.

\footnotetext{
${ }^{5}$ We focus here on the effects of maternity leave. As discussed, several European countries have also instituted paid paternity leave or have passed laws reserving a portion of parental leave for fathers (so called "daddy quotas"). While several studies have examined the effects of these laws on father involvement, employment, and earnings (see e.g. Ekberg et al., 2005; Johansson, 2010; Rege and Solli, 2010) there is little evidence to date on the effects of these programs on child outcomes. An exception is a recent Norwegian study that finds that setting aside a month of paid leave for fathers led to improved school performance for children when assessed at age 16, but only for those whose fathers were more highly educated than their mothers (Cools, Fiva, and Kirkeboen, 2011).
} 


\section{Studies assessing effects on young adults or adolescents}

DENMARK - Rasmussen (2010) examines the effects of a reform that extended parental leave benefits from 14 weeks to 20 weeks in 1984. She first presents data showing that actual leave use increased by about 6 weeks following the reform, suggesting that take-up of the extended benefits was high. She then uses a regression discontinuity design - where the treatment group includes children born during the two months immediately following the effective date of the leave expansion and the controls are those born in the two months before it - to analyze data on young adults' high school enrollment and completion,and high school grade point average (GPA) measured at age $21 .{ }^{6}$ Rasmussen estimates that the reform had no effect on either outcome, with fairly precise estimates that reject the possibility of strong positive or negative impacts. Robustness tests using a difference-in-difference method and examining an alternative outcome (test scores from PISA for 15-year olds) yield similar conclusions. These results indicate that extending maternal time at home from 14 to 20 weeks did not affect later child outcomes, perhaps because the quality of the alternative to parental care, Danish child care, was highto start with and may even have improved with fewer children in care at young ages.

GERMANY - Dustmann and Schonberg (2008) use regression discontinuity and differencein-difference methods to analyse the effects of three reforms to maternity leave provisions in Germany: the first in 1979 extending paid leave from 2 to 6 months; the second in 1986 lengthening paid leave from 6 to 10 months; and the third in 1992 increasing unpaid leave from 18 to 36 months. ${ }^{7}$ Each of these reforms reduced the share of women working during the affected period, with the largest effects for the first reform (which the authors estimate affected some 10-15 percent of new mothers). In addition, the third reform reduced family incomes (since it extended leave but without pay). For the 1979 reform, they examine the effect on wages and unemployment for youth age 25-26 and find no evidence of positive consequences, but with the caveat that they can only observe wages for those in regular employment and no longer in schooling. For the 1986 policy change, they study the impact on the type of high school the youth attended or had graduated from by age 18-20 (in the German system, only one type, gymnasium, provides direct access to university education) and again find no evidence of benefits of the extension. For the 1992 reform, they analyze the type of high school attended at age 13-14 as well as grade attendance and grade repetition; again theyfind no support for the hypothesis that longer leaves improved child outcomes, and the data reject the possibility of large benefits for children.

NORWAY - Carneiro, Loken, and Salvanes (2010) study a 1977 reform that increased paid maternity leave entitlements from 0 to 4 months and unpaid entitlements from 3 to 12 months.

\footnotetext{
${ }^{6}$ Researchers have previously used RD designs to examine how parental leave reforms affect other outcomes. For instance, Lalive and Zweimüller (2009) use Austrian social security data to investigate how increases in parental leave durations from one to two years and then a subsequent decrease to eighteen months affected the fertility and return to work decisions of Austrian mothers.

${ }^{7}$ Their primary RD approach involves comparing outcomes for children born one month before and after the reforms. They then further compare these differences to those for children born in corresponding months in earlier or later years (where there was no policy change and so any differences will be unrelated to policy).
} 
They document that the reform led to an approximately 4 monthincrease in maternal time at home (from an average of 8 months pre-reform to 12 months post-reform). Combining regression discontinuity with difference-in-differences and examining outcomes for young adults as late as age 29, they find that the reform decreased high school dropout rates. ${ }^{8}$ The largest effects were observed for children of the least educated mothers and for those whose mothers would have been expected to take the least leave prior to the reforms (i.e. mothers who pre-reform would have been anticipated to take 0.4 to 5.1 months of leave). They also find positive impacts of the leave expansions on male IQ and height (outcomes they observe only for men because they are obtained from military draft data). The authors suggest that they identify long-term benefits of maternity leave extensions, whereas other studies do not, because they focus on women who were eligible under the reforms, rather than all new mothers, and also because the policy change they study extended leave in the first year of life and without reducing family income. ${ }^{9}$ They also note that the counter-factual in Norway during this time period would have been informal child care rather than the high-quality child care and education on offer in many European countries in later years.

SWEDEN - Liu and Skans (2010) study a reform extending parental leave benefits from 12 months to 15 months for children born beginning in October $1988 .{ }^{10}$ Theyuse a difference-indifference approach that relies on variations in leave entitlements available during 1988, with data from 1987 and 1989 also included to purge the model of season-of-birth effects. They document very high parental leave take-up, with the result that the policy change effectively increased the amount of time new mothers stayed home by up to 3 months, while also reducing the share of children in non-parental care. Analysing test scores and grades at age 16, the authors find no average effect of the reform on school performance and are able to reject the possibility of large benefits. However, the results vary by maternal education, with children of well-educated mothers (those with at least some education beyond secondary school) benefiting from the extension. These results suggest that children with well-educated parents do gain from being home with their parents (and delaying entry into child care) at 1215 months. A likely reason is because the quality of parental care in these families exceeds the quality of non-parental care, whereas this is not the case in less educated households.

\section{Studies assessing effects on young children}

CANADA - Baker and Milligan (2008, 2010, 2011) examine the effects of a maternity leave reform enacted in 2000, extending the period of paid maternity leave from 6 months to 12

\footnotetext{
${ }^{8}$ Their identification strategy is similar to Dustmann and Schonberg (2008). Specifically, they use an RD approach comparing results for children born just before versus just after the reforms and then compare these differences to those for three control groups - children born at the same time but whose mothers were ineligible for parental leave, and those with eligible mothers but born in the same calendar months either two years earlier or two years later.

${ }^{9}$ When they ignore eligibility, they cannot reject that the policy reforms have no effect.

${ }^{10}$ Leave was extended by one month for children born in August of 1988 and by two months for those born in September.
} 
months for most of Canada. ${ }^{11}$ Children born to single parent households are omitted from the analysis because they would have been affected by other related policy changes. Their main results rely on an IV strategy, where the key independent variable is the number of months the mother spends at home with her child during the first year of life, and this is instrumented by whether the child was born before or after December 31, 2000, when the maternity leave expansion took effect. ${ }^{12}$ Baker and Milligan (2008) show that for treated mothers the reform increased time at home by 3 months, from an average of 6 months to 9 months, and increased the duration of breast-feeding by 1 month. Focusing on health and developmental outcomes for children up to age 24 months, Baker and Milligan (2010) uncover no evidence of favorable effects of the reform. Analyzing health and developmental outcomes for children age 4-5 years, Baker and Milligan (2011) again find little indication of positive impacts (they note some small possible benefits in terms of behavior, but also some small detriments in terms of cognitive development). Haeck (2011) also analyzes 4-5 year olds and finds the effects vary depending on the method used. Applying standard difference-in-difference methods she finds no effects (in line with Baker and Milligan, 2011) but when applying matching difference-in-difference methods, the maternity leave extension is estimated to have positive effects on children's health and cognitive development, and on related aspects of family functioning.

U.S. - A recent study by Washbrook, Ruhm, Waldfogel, and Han (2011) investigates the effects of state maternity leave laws and two related policies (welfare related work extensions and child care subsidies) on children's school readiness, using data from a large nationally representative birth cohort, the Early Childhood Longitudinal Study - Birth Cohort. The authors apply a DD method to the data available for a single cohort by considering differences between states with and without specified policies and for treatment (control) groups expected to be strongly (weakly or not at all) affected by the policies. For instance, the parental leave policies considered are state laws that extend beyond the federal Family and Medical Leave Act (FMLA), with the treatment (control) groups consisting of mothers who did (did not) work in the year prior to pregnancy. More generous state maternity leave laws are found to increase mother's medium-term employment, leave-taking, and the use of nonparental child care in the first year post-birth; however, they do not significantly affect child health or development at age 4. The authors speculate that the changes induced by the limited U.S. policies are not large enough to produce sizable changes in child outcomes.

\footnotetext{
${ }^{11}$ The most important exception was that Quebec provided 70 weeks of leave both before after the reform. Two providences, Saskatchewan and Alberta, did not change the duration of job-protected leave until 2001. ${ }^{12}$ They cannot easily use the RD approaches discussed for the European studies because they use survey, rather than administrative, data and so do not have large numbers of observations for children born immediately before and after the policy reforms.
} 


\section{Early childhood education}

\subsection{Origins and current situation}

A good deal of attention has been focused recently on the potential role of early childhood education forimproving child health and development, and narrowing gaps in outcomes between disadvantaged children and their more advantaged peers. Yet the evidence on which such claims are based has, until recently, been quite restricted, deriving mainly from a limitednumber of small-scale trials that delivered early childhood services to disadvantaged children in the U.S. These trials show convincingly that high-quality early childhood education can improve child outcomes, particularly for the disadvantaged, and can yield benefits exceeding costs. ${ }^{13}$ Evidence on Head Start, a compensatory early education program targeted to low-income children in the U.S., has also shown positive impacts for the disadvantaged children served by this program. ${ }^{14}$ But evidence on large-scale or universal programs has been lacking. Yet this is exactly the evidence needed by policymakers in countries such as the U.S., which lack large-scale or universal programs, as they consider whether to move forward with such programs.

Fortunately, while the U.S. has been studying its small-scale trial programs and its compensatory Head Start program, a number of countries around the world have implemented large-scale or universal programs. Indeed, it has become normative in many countries for the state to provide publicly funded and universal preschool for children beginning at age three or four, typically a year or two before the start of formal school entry (Organization for Economic Cooperation and Development, 2006). Do such programs improve child outcomes and help close achievement gaps between disadvantaged and advantaged children? Policymakers introducing and supporting such programs assume this is the case, but until recently the effects of these universal programs on child outcomes hadnot been studied.

However, burgeoning recent researchsheds light on whether large-scale or universal provision of early childhood education improves child health and development, and narrows gaps in those domains. We focus on these new studies next. We are particularly interested in analysesthat shed light on long-term effects but also review researchproviding evidence about

\footnotetext{
${ }^{13}$ The results have been convincing, in part, because some of these trials involved experimental designs - where children were randomly placed in the treatment and control groups. Probably the most famous example is the Perry Preschool project, which randomized 123 children in Ypsilanti (Michigan). The treatment group received 2.5 hours a day of educationally-oriented preschool, along with weekly home visits by teachers. Long-term gains, now evaluated through age 40, have been observed for the treatment group along a variety of dimensions including educational attainment, employment and earnings, and social dimensions such as reduced criminality (see e.g. Karoly et al., 2005; Heckman et al., 2010).

${ }^{14}$ The strongest evidence on Head Start comes from a recent experimental study, the Head Start Impact Study (HSIS) as well as several econometric studies that have used rigorous methods (e.g. family fixed effects, regression discontinuity) to control for selection bias. The HSIS found short-term gains, which faded somewhat following program completion; the econometric studies, which have been able to follow children for longer periods of time, have found positive effects on medium- and long-term outcomes (see reviews in Almond and Currie, 2011; Blau and Currie, 2006; Gibbs, Ludwig, and Miller, 2011).
} 
medium- and short-term consequences, where these provide information about outcomes such as test scores or school progression that can plausibly be related to longer-term effects.

The expected effects of universal early childhood education policies on long-term outcomes for children will depend on several factors. In general, results will depend on whether and how the policies affect children's care arrangements, as well as their influence on mediating factors like parental employment and income. In particular, the effect of such policies will depend on the quality and type of early childhood care and education provided, the population to whom it is provided, and the age of the children when they are enrolled. In addition, the effects of such policies will depend on the counter-factual: early education reforms that move children into school or center based settings from low quality informal care arrangements will have a different effect than those that move children from parental care. Thus, the effects of early childhood education reforms may not be uniform across countries or time periods.

\subsection{The evidence}

We begin with studies that have followed children exposed to universal preschool through adulthood, providing information about effects on long-term outcomes such as completed schooling, employment, and earnings. We then turn to research that has followed children to adolescence, supplying evidence on effects on medium-term outcomes such as middle school or secondary school test scores and grade retention. We conclude with more recent analyses of the effects of universal preschool programs on school readiness or primary school outcomes.

\section{Studies assessingeffects on adult outcomes}

DENMARK - Bingley and Westergaard-Nielsen (in press) analyze long-term effects of preschool expansions that occurred in the late 1970s and early 1980s, using OLS regression techniques. They estimate the effect of area preschool density when the child was aged 0-6 on completed schooling and earnings at age 22-30. Preschool density is positively associated with completed schooling, and this effect tends to be larger for disadvantaged children, particularly daughters of less-educated mothers. There is also a favorable impact of preschool density on adult earnings, although the evidence is mixed as to whether this effect varies by family background.

FRANCE - Dumas and Lefranc (in press) use standard regression methods and IV techniques to evaluate long-term effects of the preschool expansions that occurred in the 1960s and 1970s, a period when the share of 3 year olds enrolled in preschool rose from 35 percent to 90 percent, while the share of 4 year olds enrolled grew from 60 percent to 100 percent. ${ }^{15}$ They uncover positive impacts of preschool on grade repetition, test scores, high school

\footnotetext{
${ }^{15}$ Identification in the IV models relies on regional variations in the access to preschool in the 1970s.
} 
graduation, as well as on adult wages. These effects are particularly large for children from disadvantaged or intermediate (rather than advantaged) backgrounds. ${ }^{16}$

NORWAY - Several studies investigate the effects of preschool in Norway.Here we discuss examinations of long-termconsequences. Havnes and Mogstad (2011) study the preschool expansions that occurred following passage of the Kindergarten Act in 1975, after which federal preschool funding increased dramatically, especially in the late 1970s, and the share of 3 to 6 year olds for whom there was a subsidized child care slot rose almost threefoldfrom under 10 percent in 1975 to over 28 percent in 1979.The authors use data on young adults aged 30-33 and apply a difference-in-difference methodology that is identified by municipality disparities in the amount by which the reform increased the availability of child care. ${ }^{17}$ Expanded preschool availability is found to raise children's subsequent educational attainment (more years of schooling, higher rate of college attendance, and lower rate of high school dropout) and labor market participation, while reducing welfare receipt. Effects were largest for children of low-educated mothers. In terms of mechanisms, the expansion of preschool did not induce more maternal labor supply; rather, it led families to use more formal child care in place of informal care.

U.S. - There are no studies estimating long-term effects of universal prekindergarten programs, because these have only recently been introduced in the U.S. (studies examiningimpacts on medium- and short-term outcomes are discussed below). However, there is research investigating the consequences ofintroducingkindergarten programs (serving children age 5).Cascio (2009, 2010) exploits data on the differential timing of state funding,during the 1960s and 1970s, to examine the long-run effects of kindergarten. ${ }^{18}$ She finds that universal kindergarten reduced the share of 21 to 35 year old adults who were high school dropouts or were incarcerated; however, these effects are found only for whites. The absence of comparable effects for blacks may have occurred because kindergarten substituted for enrollment in other early childhood education programs (in particular, Head Start) for many poor black children.No effect of kindergarten is found on public assistance receipt, employment, or earnings for either racial group.Using a similar empirical strategy, Dhuey (2011) analyses long-term effects of the same kindergarten expansions on theeducational and labor market outcomes for adult males aged 30-50. She finds marginally significant positive effects of kindergarten availability on the share with at least some college, weeks worked, and wages for Hispanic men, but no corresponding effectsfor white or black males. She hypothesizes that the effects may be larger for Hispanics because, in the absence of kindergarten, they are less likely to attend educationally-oriented preschools and are more likely to be placed in informal non-center based care.

\footnotetext{
${ }^{16}$ Two French studies (Caille, 2001; Goux and Maurin, 2010) examine the short-term effects of recent extensions of preschool to 2-year olds. We discuss these in a later section.

${ }^{17}$ Municipalities with above the median percentage point growth in child care coverage rates constitute the treatment group; those below the median are in the comparison group.

${ }^{18}$ Nineteen states began funding kindergarten for the first time between 1966 and 1975.
} 


\section{Studies assessing effects on adolescents}

GERMANY - Spiess, Büchel, and Wagner (2003) use data from the German SocioEconomic Panel (GSOEP) for 1984-1994 to examine how kindergarten attendance is related to $7^{\text {th }}$ grade school placement. Identification is based on a relatively limited set of controls and the authors acknowledge the possibility that kindergarten attendance differs based on unobserved characteristics. ${ }^{19}$ Noting this potential shortcoming, no effect of kindergarten is found for German citizens; however, immigrants attending kindergarten are more likely to be placed in the intermediate (Realschule) or university preparatory (Gymnasium) tracks and much less often placed in the less demanding Hauptschule track (the probability of attending the least demanding track is predicted to decrease from 72 to 46 percent for immigrant children who attended kindergarten, versus those who did not).

INDIA - Hazarika and Viren (2010) analyse how attending government sponsored early childhood developmental facilities (called Anganwadi), analogous facilities run by nongovernmental organizations, or preschool classrooms, fromage $0-6$, is related to school enrollment and grade progression at ages 7-19. Since participation is potentially endogenous, they use an IV approach with enrollment in an early childhood developmental program instrumented by presence in the village of an Anganwadi center or a school offering preschool classes. Previous participation in an early childhood program is estimated to raise the school enrollment of 7-19 year olds by 31 percentage points - with strong positive effects estimated for both 7-12 and 13-19 year olds - and also speeds grade progression conditional on enrollment.

NORWAY - Black, Devereux, Loken, and Salvanes (2010) examine the effects of government subsidized preschool on national exam grades for children at age 16, using variation in child care prices as an instrument for preschool attendance. Preschool attendance at age 3-5 is found to have a positive effect on children's future national exam grades, with the largest impacts for children from low-income families. (Results by mother's education level are mixed.) Drange and Kjetil (2010) use a difference-in-difference approach to study the 1988 introduction of free preschool for 5-year olds in two districts in Oslo (which eliminated co-payments otherwise required of parents). ${ }^{20}$ The program was intended to raise school achievement of children of immigrants and the authors find that it did lead to higher grade point averages at age 16 for these children; however, this effect was significant only for girls.

SWEDEN - Fredriksson, Hall, Johansson, and Johansson (2010) analyze the effects of preschool attendance on test scores at age 13 for four cohorts of children born between 1967 and 1982, a period when preschool enrollment increased dramatically. They focus on the gap in test scores between children of immigrants and those with native-born parents, thus accounting for general cohort-specific trends (but not those differing by immigration status of the parents). Preschool attendance is found to significantly close a portion of the language

\footnotetext{
${ }^{19}$ Additional caveats include the limitation of the study to West Germany and small sample sizes (206 German citizens and 110 residents).

${ }^{20}$ The comparison group consists of children in districts that did not make preschool free of charge at this time.
} 
score disparity between children of immigrants, and their peers with native-born parents. However, preschool attendance is not observed to affect the gap in scores on another test, measuring inductive reasoning, nor whether children completed an academic secondary school degree.

URUGUAY - Berlinski, Galiani, and Manacorda (2008) analyze a government sponsored expansion in preschool provision that occurred during the late 1990s/early 2000s.Enrollment in public preschools increased 76 percent between 1995 and 2004, with particularly large growth for disadvantaged children (e.g. enrollment of children from households in the bottom quintile of the income distribution rose from 20 percent in 1991 to 60 percent in 2002). Using data on children aged 7-15 and controlling for family fixed effects to address possible selection into preschool, children who attended preschool were more likely to be enrolled in school and had completed more grades; both effects increased with child age. ${ }^{21}$ The estimatedimpacts were particularly large for children with low-educated parents or living outside the capital city, Montevideo.

U.S. - There are no studies that follow children exposed to universal prekindergarten programs to adolescence, because these programs are still quite recent in the United States. However, one of the studies discussed above in the context of effects on adults (Dhuey, 2011),finds that kindergarten expansions led to reduced grade retention among Hispanic children, non-English speakers, children of immigrants, and children from low SES households.

\section{Studies assessing effects on school readiness or primary school performance}

ARGENTINA - Berlinksi, Galiani, and Gertler (2009) analyze how a government sponsored expansion in prechool provision affectedchildren's test scores and behavior in third grade. Subsequent to a 1993 law mandating universal preschool, the government added new preschool classrooms in local primary schools between 1993 and 1999. Take-up was very high, with each new slot leading to approximately one additional child being enrolled in preschool. Using an identification strategy that exploits regional differences in the availability of new preschool spaces, the authors find that an additional year of preschool increased language and math test scores by around 0.23 of a standard deviation, and also led to improved attention, effort, class participation, and discipline. The test score effects were larger for children living in areas with relatively high poverty rates (differential effects on behavioral outcomes not reported).

CANADA - Baker, Gruber and Milligan (2008) study the introduction of a universal \$5-aday child care subisdy program for children aged 0-4 in Quebec. The program did not explicitly provide preschools or prekindergarten - and thus differs from the universal preschool programs in other countries considered here -- but instead supplied subsidies such that parents’ maximum child care expense would be \$5 per day. The program led to large

\footnotetext{
${ }^{21}$ Thus identification is based on differences in outcomes for children attending preschool compared to siblings who did not. This procedure controls for time-invariant household factors but not for potential confounding factors that differ across siblings.
} 
increases in maternal employment and in the use of non-parental child care. Using a DD strategy, changes in outcomes are compared between children in Quebec (the treatment group) and the rest of Canada (the controls). They find significant negative effects of the subsidy program on socio-emotional and health outcomes of children under the age of 5 . The authors examine a range of possible mechanisms and highlight the likely roles of strong increases in maternal labor supply that are accompanied by worse parental health and relationship quality, and more hostile, less consistent parenting. In addition, much of the expansion of child care slots was for informal care which may have relatively poor average quality. Using a similar econometric strategy, Lefebvre, Merrigan, and Roy-Desrosiers (2011) confirm that the subsidies significantly increased mothers' employment and child care use. They further demonstrate that the program had negative effects on children's vocabulary (PPVT) scores at age 5, which they attribute to the low average quality of child care available in Quebec during this period.

DENMARK - Datta Gupta and Simonsen (2010a) examine the effect of universal preschool on child behavior at age 7, taking advantage of municipality-leveldifferences in the availability of preschool slots (with children placed in family day care when preschool is unavailable). ${ }^{22}$ Children who attended preschool at age 3 (for less than 30 hours per week) do not differ in behavior from those cared for exclusively by parents, whereas those in family day care had more behavior problems than either of the other groups. In a related paper, Datta Gupta and Simonsen (2010b) reported that by age 11, children who attended family day care no longer had worse behavior than those who had attended preschool (and they did not differ on cognitive outcomes), but they liked school less. Esping-Andersen and co-authors (in press) examine the effects of attending preschool, as compared to family day care or parental care, on children's reading scores at age 11 . Using regression models that include fairly extensive controls (but do not account for unobserved heterogeneity between those attending different types of child care), they find that preschool attendees have significantly higher test scores, with the largest effects for children from the bottom of the income or reading score distributions.

FRANCE - Caille (2001) looks at how preschool enrollment at age 2 (rather than the usual age 3) is related to early school performance for children born at the beginning of the 1990s. Using logistic regression models with controls for child and family characteristics, he finds that children starting preschool at 2 are slightly less likely to be retained than those beginning at 3, with especially large effects for children of immigrants. Goux and Maurin (2008) take advantage of regional variations to examine how early (at age 2) preschool enrollment is related to subsequent school achievement, and find no evidence of significant differences.

GERMANY - Felfe and Lalive (2011) investigate how center-based care provided to 0-3 year olds affects social development, language skills and school grades measured at ages 2 through 10, exploiting differential post-unification changes in the availability of childcare slots between East and West Germany. Formal care is associated with small developmental benefits for the average child (estimated from OLS models) but large and lasting benefits for

${ }^{22}$ The sample includes children born in September or October of 1995 and followed through 2003. 
the marginal child (estimated from IV models). The difference occurs in part because the newly cared for children tend to be from low socio-economic status families where formal childcare, and the induced increases in maternal employment, are most beneficial.

U.S.-There have been several studies of the recently introduced universal pre-kindergarten programs, which now cover more than 25 percent of 4 year olds and a much smaller share (4 percent) of 3 year olds (Barnett et al., 2010; Ruhm, 2011). ${ }^{23}$ Most of this researchfocuses on school readiness, although some also examines outcomes later in primary school.

Magnuson, Ruhm, and Waldfogel (2007a and 2007b) use data from the Early Childhood Longitudinal Study-Kindergarten Cohort of children in kindergarten in 1998 to examine the effects of attending pre-kindergarten as distinct from other types of childcare or parental care. Their estimates include an exceptionally detailed set of controls for child, family, background, school and neighborhood characteristics. IV estimates are also provided in Magnuson et al. (2007a), with access to state prekindergarten used as instruments. ${ }^{24}$ They show that children, particularly those who are disadvantaged, attending prekindergarten in the year before kindergarten enter school with better math and reading skills; however, some of these gains dissipate by fifth grade (around age 11) or may be offset by later compensatory education that targets less prepared children.Additionally, Magnuson, Ruhm, and Waldfogel (2007a) find that children attending pre-kindergarten enter school with higher levels of behavior problems, which persist to first grade; however, this does not occur for those attending a prekindergarten program at their current public school.

Figlio and Roth (2009) provide further evidence on the behavioral effects of pre-kindergarten, using detailed longitudinal administrative data for children attending public school in Florida. Using an IV strategy identified by the presence or absence of a public prekindergarten program in the student's local zoned elementary school, they find that attending prekindergarten reduces behavior problems, and suspension or grade retention rates during the first few years of primary school. The largest benefits are observed for children from families with low levels of education or from disadvantaged neighborhoods.

Fitzpatrick (2008) uses data on fourth graders from the National Assessment of Educational Progress (NAEP) and a difference-in-difference methodology to show that Georgia's universal pre-kindergarten program increased the reading and math scores of disadvantaged children and those in small towns or rural areas, while reducing the probability of grade retention. ${ }^{25}$ Effects for other groups are less consistent. ${ }^{26}$

\footnotetext{
${ }^{23}$ There are also several recent investigations of child care subsidy programs for low-income families in the United States(see e.g. Herbst and Tekin, 2010a, 2010b, 2011; Johnson et al., 2011) but these targeted programs are not our focus here. Similarly, we do not discuss the many studies examining the effects of child care or preschool attendance on child outcomes (see review in Waldfogel, 2006), as they do not examine universal or large-scale preschool programs.

${ }^{24}$ Access is measured by state prekindergarten spending per poor child under the age of 6 or the fraction of children under age 6 in the state attending prekindergarten programs.

${ }^{25}$ The treatment group consists of Georgia children turning4 years old on or after September 1, 1995. The comparison group includes Georgia children turning 4 before that date, as well as children in other states. ${ }^{26}$ In related work, Fitzpatrick (2010) examines the effects of universal pre-kindergarten programs in Georgia and Oklahoma on children's preschool enrollment and mothers' employment.Universal pre-kindergarten is
} 
Gormley and co-authors (2005, 2008) have carried out several studies of Oklahoma's universal pre-kindergarten program. Using a regression discontinuity method, taking advantage of the birthday cut-off for enrollment, they find positive effects on children's literacy and math, as well as socio-emotional development, with the largest benefits for disadvantaged children. Wong and co-authors (2008) apply a similar RD approach to analyse the effects of five state pre-kindergarten programs (in Missouri, Oklahoma, New Jersey, South Carolina, and Wyoming). The results vary somewhat by state but, overall, are positive for language skills, literacy, and math. ${ }^{27}$

\section{Discussion}

Research on the long-run effects of parental leave and early childhood education policies is growing rapidly, but we cannot yet say with confidence exactly what the consequences of these policies are. In part, this uncertainty results from the extensive data demands required to conduct such research and becauseaverage effects may depend on the details of the policies implemented and of the institutional environment (e.g. the quality and affordability of nonparental child care). Despite this uncertainty, some trends are beginning to emerge.

Expansions of parental leave policies may be desirable for a variety of reasons, including their role in improving the labor market outcomes of women, assisting families in balancing the competing demands of home and the workplace, and possibly improving maternal and child health. However, there is currently only limited evidence that expansions of leave durations in Europe have led to long-run improvements in educational or labor market outcomes of the children whose parents are affected by them. One possibility is that such benefits are hard to measure or are confined to specific sub-groups. This would be the case, for instance, where benefit extensions affected relatively few parents or where effects varied among those covered. Consistent with this, we note that in Carneiro et al's (2010) study of the Norwegian expansions, no effects were uncovered when the analysis sample includes parents likely to be ineligible for the benefit increases. Conversely, beneficial consquences were found when the estimates were focused upon the women likely to be influenced by the expansions. A second potential explanation is that leave durations in Europe were sufficiently long, even before recent extensions, so as to yield most of the possible benefits to children. Investments of parental time may have a particularly high return when they occur at the very beginning of the child's life and European countries have long provided leave during this period. Consistent with this, we note that the strongest evidence of long-term gains is in Carneiro et al.'s (2010) study of the Norwegian expansion of paid leave from zero to four months, covering precisely the very young child ages where gains may be particularly large. This distinction is also relevant when considering policy changes in the United States, where rights to paid leave are almost completely absent, and entitlements to short unpaid leave are available to some but not all new parents.

shown to raisepreschool enrollment by at least 14 percent but with little effect on mothers' employment, except in rural areas.

${ }^{27}$ Studies of other individual state programs also report benefits of pre-kindergarten at school entry, as well as some positive effects sustained until later grades. These studies (of programs in California, Louisiana, Michigan, New Jersey, New Mexico, North Carolina, and Tennessee) are reviewed in Barnett et al., 2010; see also Weiland and Yoshikawa (2010) who study a pre-kindergarten program in Massachusetts. 
By contrast, the results are far more uniform for research examining early childhood education. Expansions of these programs, to cover either more children of a given age or younger children, are found to yield benefits at school entry, in adolescence, or for adults in virtually all studies. Generally, these gains are largest for those who are disadvantaged (e.g. those who come from low-income or immigrant households) and in many studies the positive effects are largely restricted to these groups. Exceptions to this pattern are obtained in some U.S. investigations, probably because high quality subsidized child care had been available to many low-income childrenthrough Head Start, even before the expansions. Similarly, the mixed or negative results obtained in Canada probably occurred because the expanded child care subsidies increased the use of relatively low-quality informal care (and simultaneously raised maternal employment).

These findings suggest that expansions of early child care and education yield benefits but with two caveats. First, obtaining these favorable consequences requires an institutional structure where high quality non-parental care is available and affordable. Second, the gains are generally largest for disadvantaged children. This suggests that the case for expansions of high quality early education targeting disadvantaged children is stronger than that for universal programs. However, universality may have other advantages. For example, it may increase political support for maintaining high program quality and foster a unity of national early childhood experiences.Moreover, most of the aforementioned benefits observed for disadvantaged children came from universal programs and we cannot conclude that narrowly targeted programs would necessarily have the same effects.

There is much scope for interesting future research. Our current understanding of long-term consequences remains quite limited, in part because many interesting policy innovations have not been in place for a sufficient period of time to observe such effects with confidence. In addition, longer elapsed time periods between early childhood and the outcomes of interestwould permit the study of potential mediating and moderating factors, the effects of which are quite challenging to account for. Moreover, the set of dependent variables previously examined isrelatively restricted, most often focusing on educational and labor market outcomes. For example, we know almost nothing about the medium-or longer-run effects of these programs forhealth, family functioning, criminality, social cohesion, or happiness, all of which represent important topics for subsequent investigation. 


\section{References}

Almond, Douglas, and Currie, Janet (2011).“Human capital development before age five.” In Orley Ashenfelter and David Card (eds). Handbook of Labor Economics.Amsterdam: North Holland.

Baker, Michael, Gruber, Jonathan, and Milligan, Kevin. (2008). "Universal child care, maternal labor supply and family well-being.” Journal of Political Economy 116(41): 709745. (2008b)

Baker, Michael and Milligan, Kevin (2008). "Maternal employment, breastfeeding, and health: Evidence from maternity leave mandates.” Journal of Health Economics 27(4): 871887.

Baker, Michael, and Milligan, Kevin (2010). "Evidence from maternity leave expansions of the impactof maternal care on early child development.” Journal of Human Resources 45(1): $1-32$.

Baker, Michael and Milligan, Kevin (2011). "Maternity leave and children’s cognitive and behavioral development.” NBER Working Paper No. 17105.

Barnett, Steven, Epstein, Dale, Carolan, Megan, Fitzgerald, Jen, Ackerman, Debra, and Friedman, Alison (2010). The State of Preschool, 2010.Rutgers University, National Institute for Early Education Research. Available at: http://nieer.org/yearbook/pdf/yearbook.pdf.

Berlinski, Samuel, Galiani, Sebastian, and Gertler, Paul (2009). "The effect of pre-primary education on primary school performance.” Journal of Public Economics 93(1-2): 219-234.

Berlinski, Samuel, Galiani, Sebastian, and Manacorda, Marco (2008). "Giving children a better start: Pre-school attendance and school-age profiles.” Journal of Public Economics 92(5-6): 1416-1440.

Bingley, Paul, and Westergaard-Nielsen, Niels (in press). "Intergenerational transmission and day care in Denmark.” In Ermisch, John, Jantti, Markus, and Smeeding Timothy (eds).Inequality from Childhood to Adulthood: A Cross-National Perspective on the Transmission of Advantage. New York: Russell Sage Foundation.

Black, Sandra, Devereux, Paul, Loken, Katrine, and Salvanes, Kjell (2010). “The perils of pre-school? The effect of child care on academic performance.” Available at: http://client.norc.org/jole/soleweb/11228.pdf.

Blau, David and Currie, Janet (2006). “Pre-school, day care, and after-school care: Who's minding the kids?” Pp. 1163-1278 in Hanushek, Eric and Welch, Finis (eds) Handbook of the Economics of Education, Volume 2.Amsterdam: North Holland. 
Caille, Jean-Paul (2001). “Scolarisation à 2 ans et réussite de la carrière scolaire au début de l'école élémentaire.“ Éducations et Formations 60 : 7-18. Available

at: ftp://trf.education.gouv.fr/pub/edutel/dpd/revue60/article1.pdf.

Carneiro, Pedro, Løken, Katrine, and Salvanes, Kjell. 2010. “A Flying Start? Long-Term Consequences of Maternal Time Investments in Children During Their First Year of Life.” IZA Discussion Paper No. 5362.

Cascio, Elizabeth (2009). "Do investments in universal early education pay off? Long-term effects of introducing kindergarten into public schools.” NBER Working Paper 14951.

Cascio, Elizabeth (2010). “What happened when kindergarten went universal?” Education Next, 10(2), 62-69.

Cools, Sara, Fiva, Jon, and Kirkeboen, Lars (2011). "Causal effects of paternity leave on children and parents.” CESifo working paper.

Cunha, Flavio and Heckman, James (2007). “The technology of skill formation.” American Economic Review 97(2), 31-47.

Datta Gupta, Nabanita and Simonsen, Marianne (2010a). "Non-cognitive child outcomes and universal high-quality child care.” Journal of Public Economics 94(1-2): 30-43.

Datta Gupta, Nabanita and Simonsen, Marianne (2010b). "Where to put the kids? Effects of type of non-parental child care on pre-teen skills and risky behavior.” Available at: https://www.appam.org/conferences/fall/boston2010/sessions/downloads/1131.2.pdf.

Dhuey, Elizabeth (2011). "Who benefits from kindergarten? Evidence from the introduction of state subsidization.” Education Evaluation and Policy Analysis 33(1), 3-22.

Drange, Nina and Telle, Kjetil (2010). "The effect of preschool on the school performance of children from immigrant families: Results from an introduction of free preschool in two districts in Oslo.” Available at: http://www.ssb.no/publikasjoner/DP/pdf/dp631.pdf.

Dumas, Christelle, and Lefranc, Arnaud (in press). "Early schooling and later outcomes: Evidence from pre-school extension in France.” In Ermisch, John, Jantti, Markus, and Smeeding Timothy (eds). Inequality from Childhood to Adulthood: A Cross-National Perspective on the Transmission of Advantage.New York: Russell Sage Foundation.

Dustmann, Christian and Schönberg, Ute (2008). "The effect of expansions in maternity leave coverage on children's long-term outcomes.” IZA Discussion Paper No. 3605. 
Ekberg, John, Eriksson, Rickard, and Friebel, Guido (2005). "Parental leave - a policy evaluation of the Swedish 'daddy month' reform.” IZA Discussion Paper No. 1617.

Esping-Andersen, Gosta, Garfinkel, Irwin, Han, Wen-Jui, Magnuson, Katherine, Wagner, Sander, and Waldfogel, Jane (in press). "Child care and school performance in Denmark and the United States."Children and Youth Services Review.

Felfe, Christina and Rafael Lalive (2011). "How does early childcare affect child development? Learning from the children of German unification.” Mimeo, University of St. Gallen, May.

Figlio, David and Roth, Jeffrey (2009). "The behavioral consequences of pre-kindergarten participation for disadvantaged youth.” Pp. 15-42 in Gruber, Jonathan (ed) The Problems of Disadvantaged Youth: An Economic Perspective. Chicago: University of Chicago Press.

Fitzpatrick, Maria (2008). "Starting school at four: The effect of universal pre-kindergarten on children's academic achievement.” The B.E. Journal of Economic Analysis and Policy 8(1): Article 46. Available at: http://www.bepress.com/bejeap/vol8/iss1/art46.

Fitzpatrick, Maria (2010). "Preschoolers enrolled and mothers at work? The effects of universal pre-kindergarten.” Journal of Labor Economics 28(1), 51-85.

Fredriksson, Peter, Hall, Caroline, Johansson, Elly-Ann, and Johansson, Per (2010). "Do preschool interventions further the integration of immigrants? Evidence from Sweden.” In Johansson, Elly-Ann (ed).Essays on Schooling, Gender, and Parental Leave, Economic Studies 121, Department of Economics, Uppsala University.

Gibbs, Chloe, Ludwig, Jens, and Miller, Douglas (2011). “Does Head Start do any lasting good?” NBER Working Paper 17452.Available at www.nber.org.

Gormley, William, Gayer, Ted, Phillips, Deborah, and Dawson, Brittany (2005). "The effects of universal pre-K on cognitive development.” Developmental Psychology 41(6): 872-884.

Gormley, William, Phillips, Deborah, and Gayer, Ted (2008). "Preschool programs can boost school readiness." Science 320: 1723-1724.

Goux, Dominique and Maurin, Eric (2010). "Public school availability for two-year olds and mothers’ labour supply.” Labour Economics 17: 951-962.

Haeck, Catherine (2011). “Increased maternity leave and children’s development measured at age four to five: An empirical analysis.” Discussion Paper, Katholieke Universitet Leuven.

Havnes, Tarjei and Mogstad, Magne (2011). "No child left behind: Subsidized child care and children’s long-run outcomes.” American Economic Journal: Economic Policy 3(May): 97129. 
Hazarika, Gautam and Viren, Vejoya (2010). “The effect of early childhood developmental program attendance on future school enrolment and grade progression in rural north India”, IZA discussion paper no. 5209, September.

Heckman, James J. (2008). “Schools, skills, and synapses.” Economic Inquiry 46(3): 289-324.

Heckman, James J., Moon, Seong Hyeok, Pinto, Rodrigo, Savelyev, Peter A., and Yavitz, Adam (2010). “The Rate of the Return to the HighScope Perry Preschool Program.” Journal of Public Economics, 94(1-2): 114-128, (2010).

Herbst, Chris and Tekin, Erdal (2010a). “Child care subsidies and child development.” Economics of Education Review 29(4): 618-638.

Herbst, Chris and Tekin, Erdal (2010b). "The impact of child care subsidies on child wellbeing: Evidence from geographic variation in the distance to social service agencies.” NBER Working Paper16250, available at www.nber.org.

Herbst, Chris and Tekin, Erdal (2011). "Child care subsidies and childhood obesity.” Review of Economics of the Household9(3): 349-378.

Johansson, Elly-Ann (2010).“The effect of own and spousal parental leave on earnings.”IFAU working paper 2010:4.

Johnson, Anna, Ryan, Rebecca, and Brooks-Gunn, Jeanne (2011). “Child care subsidies: Do they impact the quality of care children experience?” Unpublished paper, Columbia University.

Karoly, Lynn, Kilburn, Rebecca, and Cannon, Jill (2005). Early Childhood Interventions: Proven Results, Future Promise. Santa Monica, CA: RAND.

Lalive, Rafael and Zweimüller, Josef (2009). "How does parental leave affect fertility and return to work.”Quarterly Journal of Economics 124(3): 1363-1402.

Lefebvre, Pierre, Merrigan, Phillip, and Roy-Desrosiers, Francis (2011). “Quebec’s childcare universal low fees policy 10 years after: Effects, costs, and benefits.” CIRPEE Working Paper 11-01.Available at: http://www.cirpee.org/fileadmin/documents/Cahiers_2011/CIRPEE11-01.pdf.

Liu, Qian and Skans, Oskar Nordstrom (2010). "The duration of paid parental leave and children’s scholastic performance.” B.E. Journal of Economic Analysis and Policy 10(1), Article 3. 
Magnuson, Katherine, Ruhm, Christopher, and Waldfogel, Jane (2007a). "Does prekindergarten improve school preparation and performance?” Economics of Education Review 26(1): 33-51.

Magnuson, Katherine, Ruhm, Christopher, and Waldfogel, Jane (2007b). "The persistence of preschool effects: Do subsequent classroom experiences matter?” Early Childhood Research Quarterly 22(1): 18-38.

Organization for Economic Cooperation and Development (2006).Starting Strong II: Early Childhood Education and Care. Paris: Organization for Economic Cooperation and Development.

Rasmussen, Astrid Wurtz (2010). "Increasing the length of parents' birth-related leave: The effect on children's long-term educational outcomes.” Labour Economics 17: 91-100.

Rege, Mari and Solli, Ingeborg (2011). “The impact of paternity leave on father involvement.” Unpublished paper, University of Stavanger.

Ruhm, Christopher J. (1988). “The Economic Consequences of Parental Leave Mandates: Lessons from Europe.” Quarterly Journal of Economics 113(1), 285-317.

Ruhm, Christopher J. (2000). "Parental Leave and Child Health.” Journal of Health Economics 19(6), 931-60.

Ruhm, Christopher J. (2011). "Policies to assist parents with young children.” Future of Children: Work and Family 21(2), 37-68.

Spiess, C. Katharina, Büchel, Felixand Wagner, Gert G. (2003).”Children’s school placement in Germany: does kindergarten attendance matter?” Early Childhood Research Quarterly 18(2), 255-270.

Tanaka, Sakiko (2005). "Parental Leave and Child Health Across OECD Countries.” Economic Journal 15(501), F7-F28.

Waldfogel, Jane (2006). What Children Need. Cambridge, MA: Harvard University Press.

Washbrook, Elizabeth, Ruhm, Christopher, Waldfogel, Jane, and Han, Wen-Jui (2011). "Public policies, women's employment afterchildbirth, and child well-being.” B.E. Journal of Economic Analysis and Policy 11(1), Article 43.

Weiland, Christina and Yoshikawa, Hiro (2011). "The impact of an urban universal public prekindergarten program on child language, literacy, and numeracy skills at kindergarten entry.” Paper presented at the Association for Public Policy and Management Conference, Boston, MA, November 4-6, 2011. 
Wong, Vivian, Cook, Thomas, Barnett, Steven, and Jung, Kwanghee (2008).“An effectiveness-based evaluation of five state pre-kindergarten programs.” Journal of Policy Analysis and Management 27(1): 122-154. 